\title{
Play in Grade R classrooms: Diverse teacher perceptions and practices
}

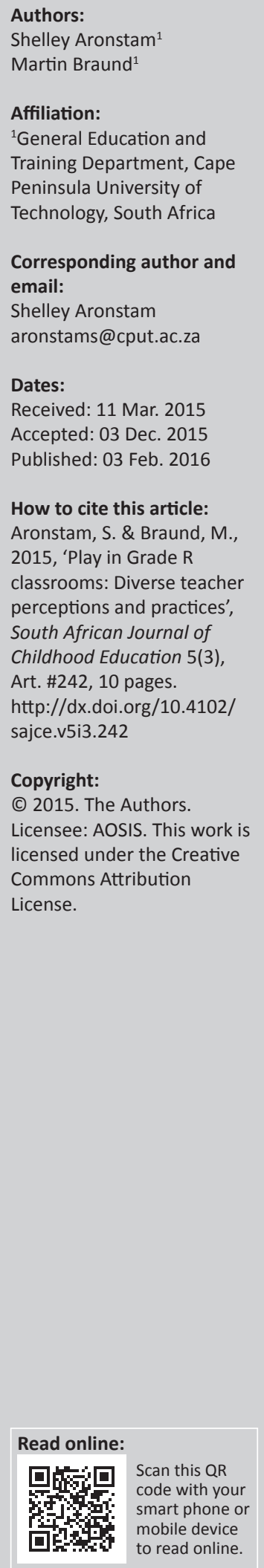

\begin{abstract}
The study explores the role of play in Grade R classrooms in the Cape Peninsula. The focus is on perceptions of teachers from differing backgrounds regarding how play is supported and utilised in the classroom. Theories of childhood play as propounded by Jean Piaget and Lev Vygotsky provide the theoretical background to our understanding of child play. Data were collected from 104 teachers in 41 primary schools and early childhood development (ECD) centres in both well-resourced and under-resourced environments, using semi-structured interviews and guided observations of practice. It was found that, although play is a difficult concept to define, it is easy to recognise. Teachers at some schools seem to have less knowledge of the pedagogy of play. Insights into early childhood teachers' views on the role of play in the curriculum have the potential to inform the planning for teacher training and national policy development for early years' learning. For these reasons, it is necessary to define and understand structured and formal play in the diverse contexts of South Africa, specifically by following, through the years, the teachers who utilise play as pedagogical tool.
\end{abstract}

\section{Introduction: play as developmental phenomenon}

Play is a human phenomenon and, in the childhood years, it is manifested in all parts of their lives in various forms or play genres (Bruner 1972). Frost and Sunderlin (1985:283) accentuate the universality of play in the young and write that, 'play is universal and knows no national or cultural boundaries'. Play is a way of life for children because it serves as a medium through which young children can explore and learn and, according to Cunningham-Burley (1990), simply develop. There is not a known author who would contradict this notion: Play is a main medium of living and developing for all children. Leading developmental psychologists have given attention to this phenomenon, including Jean Piaget (1962) who often wrote about it, and Lev Vygotsky (1967), who accentuated it in many of his unpublished works at the time when he was theorizing about child development in the 1930s.

In this article, teachers' perceptions and practices of play are scrutinised. Different definitions for formal and informal play are examined. These definitions are compared with teachers' perceptions of play. The focus here is on informal play, its place in the curriculum and the manner in which teachers respond to it. The exploration in this study is informed by structured interviews and guided observations of lessons involving play with 104 Grade R teachers in 41 schools in the Western Cape. Before discussing the research methods and providing analysis of the findings, it is necessary to discuss a few theoretical perspectives on play, how it is defined and embedded in culture, what roles teachers may have and relevant research studies, before considering the context of this study. In the conclusion section of the paper, recommendations are made on how teacher training could incorporate more appropriate knowledge and understanding of informal play as a curriculum outcome.

\section{Children constructing their world through play}

The theoretical constructs underpinning the study are chiefly associated with the constructivist epistemological writings of Piaget (1962), Bruner (1972) and Vygotsky (1967). The relationship between play and cognitive development differs in the descriptions provided by these theorists; however, they all believed that children are active in their acquisition of knowledge. Vandenberg (1986:21) remarks that, 'play not so much reflects thought (as Piaget suggests) as it creates thought'. Piaget (1962) defines play as assimilation. He states that, 'it is the child's effort to make environment stimuli match his or her own concepts' (Piaget cited in Engelbright-Fox 2008:2).

Piagetian theory fosters the belief that play itself does not essentially result in the formation of new cognitive formations, but rather it is purely for pleasure. Although play permits children to 
practise previously learned skills, it does not necessarily result in them learning anything new. Even though Piaget may be assumed to have a somewhat restricted notion of learning derived outcomes, his views remain influential in the early childhood field. This can be seen in what has been termed Developmentally Appropriate Practice (DAP). This practice draws heavily on Piaget's theory of children's engagement in active, self-initiated activities supported by responsive adults (Bredekamp \& Copple 1997). This may be one of the reasons why play is often considered by both teachers and parents as one of the key vehicles to promote learning.

By contrast Vygotsky believes that play facilitates cognitive development and is fundamental to some of the child's greatest achievements (Vygotsky 1978). His social-constructivist stance maintains that children do not only practise what they already know but that they learn new things by constructing new knowledge through their play. Engelbright-Fox (2008:2) states that, whether children are engaging in what they have learned in other settings or building on previous knowledge, it is clear that play has a valuable role in early childhood environments. Vygotsky further suggests that, there is a difference in performace between a child trying to solve a problem independently and being assisted by an adult or another child. He refers to these differences as working in the zone of proximal development or ZPD. Vygotsky refers to the process of working within ZPD as 'scaffolding', which helps bridge the difference between the child's existing level of problem-solving ability and knowledge state, and her or his capacity to tackle more complex interpretations.

Building on Vygotsky's work, Rogoff (1990) regards learning taking place through 'guided participation', which occurs when the child is in the presence of a more experienced other and through observation and action performs like an apprentice to the more knowledgeable person. Rogoff adds that when children are together without an adult, they need to decide how to play. They must negotiate meaning and agree on what they are doing and how they are going to do it. They must work together to maintain intersubjectivity, an understanding of the intentions and feelings of each other (Rogoff, cited in Smidt 2011).

Bruner refers to play as a process and mode of learning. This suggests that he saw it, 'not only as an activity in itself, but as a way of doing something' (Smidt 2011:3). Bruner maintains that when children are engaged in play, they are in the process of finding out about the world around them. Bruner discusses play as, 'memory in action ... that children play in order to remember and think about events and experiences in their lives that are no longer present in order to make sense of them' (Bruner, cited in Smidt 2011:3) Bruner saw children as actively constructing meaning, as did Vygotsky and Piaget. These views emphasise that children need opportunities to draw on their previous experiences as they engage in play activities.

Although the role of the adult is valued in Piagetian perspectives of children's learning, the importance of the adult is significantly increased if practices such as intersubjectivity and scaffolding are regarded as critical to effective learning (Rogoff 2003). Consideration must therefore be given to contemporary perspectives of children's learning; the contributions of both behaviourist and constructivist approaches to the understanding of how children learn and how educators can support and facilitate this learning. The practice of collaboration amongst peers and more experienced others, draws heavily on the sociocultural theory of Vygotsky.

\section{What is play?}

In its broadest terms, play is understood in diverse ways by different experts in the field. The word play is usually associated with children and is generally considered to be an active, enjoyable, informal activity that children engage in voluntarily (Siraj-Blatchford \& Sylva 2004). Informal or free play is often thought to be open-ended with unlimited possibilities (Bodrova \& Leong 2005; Elkind 2007; Frost 1992). Some professionals involved in the field of early childhood education refer to formal or structured play as organised activity with specific objectives and sets of rules (Vygotsky 1967; Wood 2009). From the readings of the literature on play, there appears to be no one clear definition for formal and informal play. Fisher et al. (2008), reveal that some parents share beliefs with educators that the value of play is, to some extent, most commonly associated with formal rather than informal activities. Characteristics of play are crucial for teachers to bear in mind. When adults attach their values or motivations to children's activities, it modifies the nature of a child's play. Csikszentmihalyi (1981:14) clarifies play as, 'a subset of life ... an arrangement in which one can practise behaviour without dreading its consequences'. For the purposes of this article, and taking the literature into consideration, a provisional definition can be formulated for formal and informal versions of play. Thus, we see formal play having clearly defined goals and rules. It is curriculum driven, teacher-initiated and teacher-dominated. In our opinion formal play, from this perspective, teachers perceive formal value to be of greater value because this is where learning is more easily observed. In contrast, we see informal play as, usually, without rules and intrinsically motivated. Informal play from this perspective, therefore, takes place naturally and is unplanned and spontaneous, because children participate freely.

Fatai, Faqih and Bustan (2014) believe that, when discussing the qualities of play, we should look at the word meaningful (when attached to definitions) as a descriptive qualification that suggests understanding, clarity and conception. According to this view, learning should take place during meaningful play. Lifter and Bloom (1998) believe that, during play, the child is an active participant in constructing knowledge about objects, people and events. However, in our experiences as teacher educators who frequently observe in classrooms, and from our reading of the literature, 
teachers often seem to fail to take advantage of the learning and teaching opportunities offered by informal play. This, we believe, is because teachers have different perceptions (or little perception) of the elements and outcomes of play. The lack of recognised definitions for formal and informal play contribute to why informal play is often neglected or devalued and educational purposes not being fully acknowledged. Additionally, teachers are concerned that play is not always a reliable means of achieving defined learning outcomes. According to Wood (2009), outcomes of play are often unpredictable, messy, chaotic, wild or irrational and therefore difficult to account for.

\section{Culture and play}

Izumi-Taylor, Pramling-Samuelsson and Steele Rogers (2010:1) posit that teachers' perceptions of play are influenced by their own cultures and thus can affect children's experiences in their classrooms. This historical, socio-cultural perspective is especially significant in the South African context (which we set out later). Culture is an important aspect in establishing how people in different countries regard play. Individuals with different cultural backgrounds tend to pay attention to different characteristics of the same phenomena (Azuma 1986). This applies to teachers' perspectives on play, as we are all shaped by our own cultures. Despite cultural differences, teachers in most nations recognise play as essential in children's development and learning (Izumi-Taylor, Steele Rogers \& Pramling-Samuelsson 2007). Vygotsky (1978) suggests that the cultural context significantly influences children's interests, and in turn their play. At the centre of Vygotsky's Cultural Historical Theory (1978:40) is the notion that child development is the result of interactions between children and their social environments. Therefore, a clear understanding of play-based pedagogy in diverse South African contexts' is essential. As teachers' perspectives on play are influenced by their own cultures, it has been suggested that, in play, children reproduce the cultural knowledge they have acquired in formal and informal contexts of the home, school and community (Wood 2009). Doing this involves symbolic transformation using signs and tools as children create novel meanings and relationships that are socially constructed while they exercise autonomy through play activities.

\section{Teachers and play}

There appears to be a dearth of information and research on the pedagogy of play and how it influences the learning of young children. Although play has been advocated as a key strategy in children's development, some stakeholders are still concerned about the connection between the ideology and the practice of play (Moyles, Adams \& Musgrove 2002; Sylva, Roy \& Painter 1980).

Sutton-Smith (1997) describes adults as players or play agents. He maintains that if adults are not skilled in interacting appropriately with children as they play, such participation could jeopardise the full benefits of their play. Jones and Reynolds (2011:xii) discuss the different roles teachers can occupy when working with young children. They see teachers as stage managers setting the props for learning, mediators helping children navigate the social and academic waters, players modelling the rich possibilities in play and scribes documenting learning from activities. However, the teacher is much more than a mere stage manager, mediator or player. They have a pedagogical role that is itself a product of their own perceptions of the purposes for the outcomes of play.

Central to a wider pedagogical role in play is the importance of achieving a balance between pedagogical interactions (specific behaviours on the parts of adults) and pedagogical framing involving the behind the scenes aspects of pedagogy that include planning, resources and the establishment of routines (Siraj-Blatchford \& Sylva 2004:723). This balance is evident in two projects: the Effective Provision of Preschool Experiences (EPPE) and Researching Effective Pedagogy in Early Years (REPEY) (Sylva et al. 2004). The authors discussing these projects maintain that achieving balance requires more than setting up an interesting environment to promote children's play. Educators need to go beyond this and engage children in activities. This involves identifying 'critical moments' in which there is the potential to 'lift the level of thinking' through the teacher's use of scaffolding, conversation or instruction (Siraj-Blatchford \& Sylva 2004:723). These projects reinforce the Vygotskyan, social-constructivist foundations for play discussed earlier. A distinct finding of these projects is the link to the importance of shared thinking. This is a process whereby teachers and children are mutually involved in cognitive construction. Findings from the REPEY project show that, though children may have freely chosen to play within an instructive learning environment, adult interventions may be especially effective (Siraj-Blatchford et al. 2002:40).

Through this article, we aim to heighten teachers' awareness and pedagogical understanding of the critical teaching moments that occur while children are engaged in informal play. A possible factor contributing to teachers' limited awareness of these teaching moments could be insufficient training about the benefits of informal play. Wong, Wang and Cheng (2011) propose that teachers need to follow the leads provided by children's actions and words, and be keen enough observers to identify teachable moments that move learning forwards. They argue that teacher perceptions of informal play, as free play with no adult involvement, can cloud their ability to see the valuable opportunities that enhance the child's whole development. An understanding of informal play should, therefore, assist teachers to value and utilise it to optimise learning.

The observation of learners in the classroom is critical to understanding how different children learn in a variety of situations and is why we have included this in our research. Frost (1992:48) recommends that, 'regular observations 
provide teachers with useful information for planning future play experiences, evaluating play materials, determining areas of strength and weakness for individual children and checking their on-going progress'.

\section{Studies on play in childhood}

Although studies on the efficacy and outcomes of play are rather sparse, there are some important international examples that have bear on the study reported in this article. A study in Malaysia explored ways in which unstructured play assists the general development of the preschool child (Fatai et al. 2014). The authors note that learning should take place during meaningful play since 'play nourishes every aspect of children's development' (Fatai et al. 2014:260). Findings from this study show that unstructured play encourages young learners to discover through co-operation and imitation. Unstructured play also encourages children to learn through trial and error and gain new insights into the world around them.

A comparative study of early years' teachers in Japan, America and Sweden examined similarities and differences in their perceptions of play in these countries. Izumi-Taylor, Pramling Samuelsson and Steele Rogers (2010) found that teachers' perceptions of play in America and Japan are clearly linked to their cultures. Japanese teachers were engaged in more informal play than their American counterparts who tended to believe that play should focus on learning and development. Japanese teachers considered play to be concentrated more on social and emotional development than on academic learning. Swedish teachers seemed to have quite open and creative, child-centred perceptions for play, stating that, 'in play nothing is impossible' and that, 'a chair can be changed into a boat on the open sea' (Izumi-Taylor et al. 2010:5).

A qualitative study in Hong Kong explored children's and teachers' perceptions of play and non-play and the role and influence of the cultural context on children's interests and play (Wong et al. 2011). The study found that play in classrooms is strongly teacher-directed and that teachers seem to be, 'unaware of the fact that they are actually preventing autonomous self-directed play' (Wong et al. 2011:167). In Hong Kong, where academic achievement is highly prized, teachers and parents appear to be doubtful as to the importance of play. It is regarded as an obstacle to children's success. Wong et al. (2011) maintain that, with the mix of cultural beliefs, social policies and educational practices in Hong Kong, teachers need to implement a more play-based curriculum in which play is, 'more child-initiated and self-motivated' (166).

Taken together, these studies, although in different cultural contexts and using varying terminologies, show a consensus on the values of informal play and reinforce the notion that important teachable moments, that teachers should take cognisance of, emerge from free play. There is some agreement that this requires skilled interaction on the part of the teachers and that this suggests the need for some training and professional development.

\section{Play South African learning programmes}

Since 1994, much has been done to improve the quality and availability of early learning programmes in South Africa, though we would argue that much research and investigation remains to be completed. The mandatory target set out in White Paper 5 (Department of Education 2001) states, that by 2010 , all children should attend a Grade R class before entering formal schooling. This target was not met and so the deadline was extended to 2014. At present, stakeholders believe it will take South Africa at least another 4 years to realise this goal.

Many ECD programmes still differ significantly among provinces. Obstacles such as lack of resources and learning materials, minimal funding and poor quality teacher training are still common (Department of Basic Education, Department of Social Development \& UNICEF 2010:6). A national audit of ECD commissioned by the National Department of Education, undertaken in 2000 (Atmore 2012) revealed that, of the 54503 educational practitioners working with children in early childhood sites, only $12 \%$ are qualified, $88 \%$ require additional training and $23 \%$ have no training at all. The Draft findings of the HSRC (Human Sciences Research Council) Teacher Qualification Survey (Department of Education 2009) also provide insights into the qualification status of Grade $R$ teachers. They found that of the 7380 Grade $\mathrm{R}$ teachers who completed their questionnaire, only 425 had a professional teaching qualification and only $12 \%$ had a specialisation in pre-primary teaching (Department of Education 2009:20).

Acting chief director for Curriculum and Assessment of the Department of Basic Education, Marie-Louise Samuels, stated at a seminar held by Umalusi, CEPD (Centre for Education Policy Development) and the University of Witwatersrand in 2010, that teachers who are equipped to teach Grade R are generally drawn from privileged backgrounds. She questions whether qualified teachers were offering a quality service and expressed the view that:

having a qualification is not the only determinant for teachers to do things that are expected of them; there are other factors such as designing effective learning programmes and using appropriate teaching and learning methodologies (Samuels, cited in Umalusi, CEPD \& Wits Seminar 2010:23).

At the same seminar, a participant from the Western Cape commented that, 'to improve the implementation of Grade $\mathrm{R}$ we need better qualified teachers who are registered, properly paid and who have a pride in their profession' (Umalusi et al. 2010:19). In a report by The Eastern Cape Department of Education (2008), concern was raised over the standard of learning and teaching in 250 Reception Year classrooms, because teaching programmes had been found to be of poor quality.

South African teachers have been shown to interpret the curriculum possibilities inherent in the NCS (National Curriculum Statement) in a limited manner (WSoE 2009). 
Combined with parental pressures, these limitations lead to a sense of frustration and lack of agency on the part of teachers. This affects the learners because the teacher's role as co-constructor is often undermined.

\section{Research design and methods of inquiry and analysis}

The study employs a qualitative research method was deemed to be effective in obtaining culturally specific information regarding the values, judgements and behaviour of particular populations (Denzin \& Lincoln 2000). The study was designed as an illuminative qualitative study but with facility to report findings in a semi-quantitative form, as over 100 participants were involved (104 teachers). Illuminative evaluation was developed in response to perceived limitations of traditional evaluation (Parlett \& Hamilton 1987) emphasising interpretation rather than measurement and prediction.

This study aims to understand a cohort of teachers' perceptions of informal play. When working previously with teachers (through pre-service and in-service training) we observed that informal play was often seen as children taking charge of their play with little or no adult intervention or guidance. For example, we have seen that a teacher might position herself in the playground so that she could observe learners at play. Her main focus would be on safety rather than identifying skills and interactions among the learners that could be developed. Apparently, the assumption is that many of the skills required for learning would be fostered during formal play and, so, the outcomes of informal play are not recognised and do not matter.

This study came about as a result of a project undertaken by first year student teachers training in Grade $\mathrm{R}$ at a university in the Western Cape during their teaching practice sessions. As part of their studies students were required to observe and investigate the roles of their teachers as regards formal and informal play.

Accordingly, the research participants of this study (class teachers) were purposefully selected as the student teachers had to interview and observe their class teachers to obtain data. One hundred and ten student teachers were practicing in Grade R classrooms. However, 104 teachers agreed to participate in the interviews and observations, and so that number constitutes the research sample. Data for the study were collected in two parts. The first consisted of a semistructured interview of teachers carried out by students on teaching practice using questions, designed by the researcher (author 1). The second part of data collection was from the observations and commentaries made by student teachers watching and collaborating in lessons involving play. A list of questions devised by the researcher, and related to those used in the interviews, guided student teachers' observations and comments on play. The data from this second part come from the student teachers' written records, which are a required part of their teaching practice portfolios. One hundred and four interviews and observations were completed.

The data were collected in a cross-section of schools situated in different socio-economic and cultural locations across the Cape Peninsula. Purposive, convenient sampling was used, and all teachers were in Grade R. Teachers were either in classes attached to a primary school $(80 \%)$ or in standalone classes attached to a pre-school or Educare centre. The qualifications of the respondents varied from BEd Foundation Phase degrees to Pre-Primary Diplomas as well as certificates at various levels.

The interview with teachers consisted of seven questions to obtain teachers' views and interpretations on the subject of play. The findings reported here focus specifically on four areas:

- Teachers' perceptions of formal and informal play.

- Teachers' roles in supporting and guiding play.

- Teachers' opinions on the value and benefits of play.

- The methods used by teachers to incorporate play into the daily curriculum.

The interviews and observations were carried out by firstyear Foundation Phase student teachers at a university in the Western Cape who were participating in their teaching experience in Grade $\mathrm{R}$ classrooms. The students had completed a module on different forms of play and were briefed on how to administer the interviews and carry out and comment on observations. The researcher opted to ask direct straightforward questions because the interviews were being managed by first-year students. Student teachers recorded teachers' responses, summarising them onto a simple proforma. They were instructed to confirm each response with the teacher being interviewed providing a cross-check for meaning and reliability. Using student teachers allowed access to a wide range of communities; their (the students') diverse cultural practices and languages meant they were accepted more freely. The acceptance of the interviewers fostered greater diversity and an organic, intuitive sensitivity toward teachers in the study. The interviewers' easy communication with the community and an understanding of its mores strengthened the credibility of the study and allow deeper understanding of praxis.

Interview responses and booklets were completed by student teachers who outlined their observations of lessons involving play and responded to the specific questions. These comments were scrutinised and compared independently by two researchers. The data streams were analysed according to each of the four areas listed before, which were drawn, $a$ priori, from studies of the literature. Dominant themes (that are discussed below) for each area were identified independently by two researchers through an exhaustive process, whereby all apparent themes were recorded and added. The outcomes of this exercise were compared (inter-rater reliability $=0.75$ ). 
Any disagreements on items relating to the four aspects were resolved by a discussion with a third researcher, who was not previously involved in the study. Simple descriptive statistics (percentages) were applied to the analysis of interview themes.

\section{Findings: How teachers see play in childhood programmes}

In this section, findings are presented according to the four focus areas for the study to include some of the most prominent themes identified:

- Teachers' perceptions of formal and informal play.

- Teachers' roles in supporting and guiding play.

- Teachers' opinions on the value and benefits of play.

- The methods used by teachers to incorporate play into the daily curriculum.

\section{Teachers' perceptions of formal and informal play}

Over $80 \%$ of teachers indicated, at the interviews, that they understood that children learn by means of play. They often expressed the belief that when children enjoy what they are doing and have fun, they are experiencing play. These responses were typical:

'Play is a spontaneous activity that is all about having fun-it is all about running around and doing physical activities'.

'Play is usually a game, an enjoyable activity'.

'Play is when the focus is on enjoyment rather than the outcome'.

'During formal play, I give instructions and the children follow. I like the whole class to do the same activities and I work with different micro groups'

'It is easier if the children use the materials I give them and then I sit and watch them at their tables'.

In their groups, they are taught words and numbers through games and rhymes.

A number of teachers (20\%) expressed a view that learning is a natural consequence of play. For example, one teacher at a government school said at interview: 'Play is an active way of learning. Play allows children to experiment and learn about their environment'.

Twenty percent of the teachers stated that you get two kinds of play - 'indoor and outdoor play'. For example, a few teachers $(12 \%)$ perceived outdoor play as having less structure than indoor play:

'During outdoor play, the children are allowed to express themselves and make their own rules'.

'Indoor play is a lot quieter. The children draw, look at books and do puzzles'.

It appears here that when teachers refer to learning by means of play, they are implying formal play takes place in the classroom environment. 'I prefer it if the children follow the rules that I have discussed about the board-games as this prevents arguing and fighting'; 'I cannot cope with all the children running around during free play. I have more control when it is structured'.

\section{Teachers support and guide}

All 104 teachers believed that formal play is an activity organised by the teacher with an emphasis, for example, on assessment, oral presentation, construction games, puzzles, role-play and the fantasy corner. During these play periods, they communicated that their responsibility is to provide all the resources and decide on how they should be deployed. By contrast, $80 \%$ of the teachers regard informal play as free play where children choose their own endeavours and make their own decisions regarding the activities. Children make up their own rules as they go along and decide what is acceptable amongst themselves. 'Inside the classroom the children did not play games that contained many rulesoutside, they made their own rules but these were constantly broken or changed'.

Teachers stated that informal play takes place predominantly outdoors in areas such as the sandbox and water area, including the use of outdoor equipment, ball games and general running around. Teachers set out the games and equipment while children decided how to use them. These observations were recorded by some of the student teachers:

The teacher provided the class with a board game and then the children were free to play it however they chose.

On Mondays they (the teachers) put out hula hoops. On Tuesdays (it was) balancing beams, (and on) Wednesdays (it was) gym equipment and Thursdays it is bikes. The children can use these during free play.

All teachers mentioned that outdoor play is not assessed and that their main responsibility is to monitor the children's safety. Fewer than 10\% reported that, during informal play, children use their imagination and become whatever they choose. Some typical responses in this category were:

'They used their imagination while playing in the sandpit making cakes and building castles'.

'They loved playing outside and this is where most of their creativity comes out'.

'During box construction they are able to use their imagination to create something, even with dough or clay'.

More than $60 \%$ of the teachers agreed that play should be teacher directed because formal play benefits the whole child. One teacher stated at the interview: 'I don't really like to get involved when the children play, as it is their time'.

Another reported: 'If a child asks for assistance, I will help'.

More than $50 \%$ of teachers claimed their main role during play was to make sure that no one gets hurt, and that no fighting takes place. In a few cases, discourse and interaction 
involving responses to children's questions seemed not to part of teachers' agendas.

For example, one teacher revealed that: 'If children come up to ask me questions I tell them to go back and play'.

A few teachers (10\%) indicated that play in Grade R prepares the child for formal learning in Grade 1. However, few of the respondents expressed any definite views on the progressive role of play from the Grade $\mathrm{R}$ to Grade 1 curriculum. Teachers stated that they had received limited knowledge on the pedagogy of play in their training, and believed that their role was more as observer, to ensure the safety of the learners both indoors and outdoors. Student teachers' observation records revealed:

'The teacher does not really interact or engage with the children, she just stands and watches them. If they come to her for something, she will help'.

'The teacher only gets involved if someone is hurt'.

'I did not experience any of the teachers being involved with the children during free play. They [the teachers] sit together and chat'.

Observations of classes by student teachers and their commentaries also showed that many teachers seemed unaware of their roles in promoting and supporting learning through verbal interactions with children. For example a student teacher commented that:

Most of the time the teachers just saw us (the student teachers) as facilitators and supervisors ... Only when the teacher saw a child struggling or one of their games was too rough or one-sided did the teacher intervene and only then just to say, "play it fair."

In another lesson, a student teacher commented that she could see opportunities for learning development that did not seem to occur to the teacher:

'The children offered me 'sand food' (models of food items made out of wet sand) ... so I asked them, "what are you making, how do you make it and what are the ingredients?" ... When I asked the teacher at the interview about how she implemented a playbased curriculum she chose not to say anything'.

These interpretations of actual observed practices related to play are discussed later.

\section{Teachers' opinions on the value and benefits of play}

All teachers acknowledged that there are many advantages to play. Some qualified this, adding that children are able to develop cognitive, emotional, social, perceptual and cultural skills through play. Some (36\%) also stated that play develops children's self-esteem as they often need to negotiate rules while playing games with their peers. The following responses typify this:

'Through play children gain knowledge about the world they live in'.
'It increases chances of children speaking and interacting with each other'.

'A child can have fun and learn to share with others'.

Only 10 respondents claimed that the main benefit of play is purely recreational. Ten percent claimed that, through play, children learn to solve problems, find ways to share and how to take turns. At least half the responses indicated that while children are playing, they are improving their physical development such as gross and fine motor skills:

'Gross motor skills are substantially developed during play as the children are always moving around while they are playing'.

'When the children are balancing a beanbag, they are improving their gross motor skills'.

'Play helps with co-ordination and fine motor skills.

The boys are constantly running around, while the girls prefer to walk or play inside.

\section{Methods employed to incorporate play in the daily curriculum}

All teachers stated that they integrate play with activities such as story-telling, art, movement, music and the fantasy corner. In all these activities, it appears that the teachers provide the resources and used them to incorporate play into the daily programme. These are some examples of the comments made at interview:

'It is easier if children use the materials I give them and I sit and watch them at their tables'.

'I make sure I include play in-between my lessons'.

'I let them use their imagination while playing with toys'.

'I incorporate play through educational games, songs and rhymes'.

Fifty percent of the teachers said they incorporate play as part of their weekly theme but only $12 \%$ of the teachers specified outdoor play activities as planned and detailed play. Forty percent voiced their concern about not having enough space for children to play as well as a shortage of equipment and resources:

'I don't have enough space for different areas in my classroom'.

'Space is critical to having a play-based classroom'.

'Classrooms are too small, too many children for the size of the room'.

'Our major problem is lack of space size and this impacts on how children can play'.

\section{Discussion: teachers prefer structured play}

The findings of this study show that many teachers lack personal experience or comprehension of the concept of play. The analysis indicates that play and the benefits of play are viewed as the same thing. Evidence of these teachers' understanding of play appears to be that it is controlled and structured so that they can often predict the outcome 
of activities and anticipate desired results. Observations showed that few teachers in the study appeared to regard play through the eyes of the children. It would seem that these teachers often conflated play with a means of achieving desired results or as a justification for their selection of a particular activity. These findings seems to fit with Wood (2009), who draws attention to the fact that there is considerable evidence of learning through play but that there is less evidence of teaching through play. Therefore, we would suggest that teachers need to be cognisant of the potential of formal and informal play when planning and implementing the curriculum in Grade R. The assumption that informal play is for fun, and that formal play is for learning, should be critically examined by teachers. When children are having fun, it may be that they are often at their most receptive to new stimuli and sensations and reacting to them.

The inequality of teachers' training was an important factor emerging in some interviews. Teachers at some schools (20\%), especially those in previously disadvantaged environments, appeared to be less familiar with the pedagogy of play. Their responses were an indicator of limited teaching and learning opportunities that were available to them. One teacher responded: 'It's difficult to incorporate play in the daily routine because of lack of time and resources'.

One of the student teachers in the study noted that:

'The children do their own thing and if they are doing something wrong, they wouldn't know and neither would the teacher because she is not taking note or observing the children when they play'.

This observation arose, not from a specific question in this study, but rather from the student teachers' feedback after they returned from practice and in discussion of their portfolio commentaries.

Teachers in this study seemed aware of the essential role of play in young children's lives as well as the interrelatedness to children's early development. But there still appears to be a lack of knowledge concerning how to employ spontaneous informal play moments to enhance the learning process. This was confirmed in a number of cases in which student teachers observed lack of opportunity to stimulate, engage and respond to children through verbal interaction. In discussions with students after the study, many felt that they (the student teachers) could see the possibilities and advantages of interaction, but that their teachers' common practice did not allow them to work in this way. As first year students, many felt they did not have sufficient authority to question and challenge the established practice of their teachers. Uncertainty and lack of understanding of the benefits of verbal interactions impacts how teachers assist learners in co-constructing and scaffolding from their prior knowledge during play activities.
The teachers' firm ideas about unstructured and structured play contrasts with the theoretical positions of Bruner (1972) cited in Harris (1986:23) and Piaget (1962), who maintain that play is not wasted time but rather time spent building new knowledge from previous experience. The rigidity of teachers' approaches to knowledge construction through play is problematic, especially in the light of findings by Izumi-Taylor et al. (2007) who proposed that teachers should model positive feelings about playful activities so that children witness adults successfully participating in playful environments in which there exists freedom from external rules.

This reluctance strongly and urgently signals the need for a change in attitudes so that play can be appreciated for its considerable pedagogical value and influence on how teachers plan and guide both formal and informal play in their daily curriculum. Sandberg and Pramling-Samuelsson (2003), in their findings on teachers' perspectives of play in Sweden, ask the question, 'Can play have a central role in preschools and at the same time not be reflected upon by teachers?' (Sandberg and Pramling-Samuelsson 2003:15). Even though the cohort of teachers in our study demonstrated an awareness of the value of play and the importance of providing opportunities for the learners in their classes, they still seemed to experience difficulty understanding their own crucial role during informal play. There is a disjuncture between the myriad ways children express play and the manner in which adults interpret play. These are often viewed as two distinct activities, which undermines the possible advantages of play. Teachers are often unaware or uncertain of their roles as mediators during these informal play activities. The theory of constructivist learning situates the teacher as an active co-player and co-investigator as, 'learning through play is socially mediated and constructed ... cognitive transformations occur as children move between formal and informal play and make connections between areas of knowledge and experience' (Wood 2009:6). Wood highlights the importance of the teacher as the co-constructor of knowledge who needs to take into account the sociocultural contexts and divergent understandings of young children and become more informed on the best ways for them to learn.

Mediated activities in relation to play demonstrate the teacher's awareness of play activities in a socio-cultural context. Christie (2008) cited in Excell and Linington (2011:6) maintains that the teacher as co-constructor 'lies at the heart of effective or high quality pedagogy'. The teacher thus needs to be well-informed, skilled and knowledgeable when providing opportunities for learning through play.

The theoretical background, previous research and the findings of this study illustrate how the lack of teachers' awareness of possibilities of play shapes the quality of the learning that can take place. This study is significant in the South African context, in which there is a limited body of research in the field of early childhood education. Many South African schools are still under-resourced in terms of equipment and materials. 
Training is limited and needs to be supported by sound theoretical knowledge of the different forms of play. Children need to co-construct play knowledge in order to be successful social beings. Teachers require the authority to transfer knowledge and skills between different contexts, for example about rules, roles, behaviour, social interactions, meaning and interpretation of signs and symbols, as well as the benefits of structuring of different play episodes.

\section{Conclusion: Where to with child play in the grade $\mathrm{R}$ curriculum?}

The aim of this study was to explore the role of play in Grade $\mathrm{R}$ classrooms through teachers' perceptions and practices, moderated through student teachers' observations and comments about the informal and formal play in which they participated. The findings indicate that many teachers do not display an awareness of their role during informal play and often view these occasions as purely recreational time for young children with few benefits for learning and little meaningful interaction.

The findings suggest that improving the quality of play remains a central concern in Grade $\mathrm{R}$ and any improvements in practice should be based on more detailed knowledge than is currently available on the progression of learning. To capitalise on the values of play to children's cognitive, social and cultural development, teachers must develop a more critical understanding of what different forms of play mean to individuals and groups of children. Accordingly, there should be an emphasis on equipping teachers with this information in order to provide positive opportunities for both structured and unstructured play in classrooms. To contribute to the future development of quality educator programmes for Reception Year, the implementation and design of curriculum and content at institutions of higher learning requires a strong emphasis and commitment on the role of play.

After qualification, teachers should pursue further knowledge and critical understanding of play as part of their ongoing professional development. By affording children ample opportunities to explore and experiment with various materials and stimuli, teachers can play a crucial role in guiding these experiences in a meaningful, nonthreatening way.

To achieve these improved possibilities for enlightening and educating teachers, Universities, NGOs and ECE colleges should provide more in-depth training to support the efficacy of incidental teaching moments that occur while children are playing. In 2018 (although there is still no final date of implementation of policy), all children in South Africa will be offered the opportunity to attend Grade R before starting schooling. It is now a national priority that Higher Institutions of Education play a pivotal role in teaching those who will eventually teach our children how to play and gain the most from these experiences.

\section{Acknowledgements}

We thank the student teachers and class teachers for participating in this study.

\section{Competing interests}

The authors declare that they have no financial or personal relationships which may have inappropriately influenced them in writing this article.

\section{Authors' contributions}

S.A. (CapePeninsula University of Technology) was the principal researcher, including the design of instruments, literature review and oversight of analysis. M.B. (Cape Peninsula University of Technology) adjunct professor working on research capacity development at CPUT. Assisted with the analysis, literature review and writing up of this article.

\section{References}

Atmore, E., 2012, Challenges facing early childhood development sector in South Africa, National Development Agency (NDA), Johannesburg.

Azuma, H., 1986, 'Why study child development in Japan?', in H. Stevenson, H. Azuma \& K. Hakut (eds.), Child development and education in Japan, pp. 3-12, W.H. Freeman, New York.

Bodrova, E. \& Leong, D., 2005, 'Why children need play', Scholastic Early Childhood Today 20, 1-6.

Bredekamp, S. \& Coppell, C. (eds.), 1997, Developmentally appropriate practice in early childhood programs, National Association for the Education of Young Children, Washington.

Bruner, J., 1972, 'Nature and uses of immaturity', American Psychologist 27(8), 687-708.

Christie, P., 2008, Opening the doors of learning, Heinemann, Johannesburg.

Cunningham-Burley, S., 1990, 'Mothers' beliefs about and perceptions of their children's illnesses', in S. Cunningham-Burley \& N. McKegany (eds.), Readings in medical sociology, Routledge, London.

Csikszentmihalyi, M., 1981, 'Some paradoxes in the definition of play', in A.T. Cheska (ed.), Play as context, pp. 14-26, Leisure Press, New York.

Denzin, N.K. \& Lincoln, Y.S. (eds.), 2000, Handbook of qualitative research, 2nd edn., Sage, Thousand Oaks.

Department of Basic Education, Department of Social Development \& UNICEF, 2010, Tracking public expenditures and assessing service quality in early childhood development in South Africa, DBE, Pretoria.

Department of Education, 2001, Education White Paper 5 on early childhood development: Meeting the challenges of early childhood education, DoE, Pretoria.

Department of Education, 2009, Teacher Qualifications Survey, Draft report prepared by the Human Science Research Council (Education, Science and Skills Development Research Programme) for the National Department of Education, Pretoria.

Eastern Cape Department of Education, 2008, Evaluation of the accredited training of early childhood development practitioners: Year one of a three year cycle of research: Baseline study: Quality of teaching and learning in Grade R, ECODE (Eastern Cape Department of Education), Bisho.

Elkind, D., 2007, The power of play, Da Capo Press, Berkeley.

Engelbright-Fox, J., 2008, 'Back to basics: Play in early childhood', Early Childhood News, viewed on 21 December 2011, from http://www.earlychildhoodnews.com/ earlychildhood/article_view.a

Excell, L. \& Linington, V., 2011, 'Taking the debate into action: Does the current Grade $\mathrm{R}$ practice in South Africa meet quality requirements?', South African Journal of Education 8(2), 3-12.

Fatai, I.A., Faqih, A. \& Bustan, W.K., 2014, 'Children's active learning through unstructured play in Malaysia', Childhood Education 90(4), 259-264.

Fisher, K.R., Hirsh-Pasek, K., Golinkoff, R.M. \& Gryfe, S.G., 2008, 'Conceptual split? Parents' and experts' perceptions of play in the 21st century', Journal of Applied Developmental Psychology 29, 305-316.

Frost, J.L., 1992, Play and playscapes, Delmar, Albany.

Frost, J.L. \& Sunderlin, S., 1985, 'The role of adults in promoting play: Introduction', in J.L. Frost \& S. Sunderlin (eds.), When children play, pp. 283-284, Association for Childhood Education International, Wheaton.

Harris, A.C., 1986, Child development, West Publishing, New York. 
Izumi-Taylor, S., Pramling Samuelsson, I. \& Steele Rogers, C., 2010, 'Perspectives of play in three nations: A comparative study in Japan, the United States and
Sweden', Early Childhood Research \& Practice 12(1), viewed on 10 May 2012, from Sweden', Early Childhood Research \& Prac
http://ecrp.uiuc.edu/v12nl/izumi.html

Izumi-Taylor, S., Steele Rogers, C. \& Pramling Samuelsson, I., 2007, 'Teachers' perspectives on play in Japan, the U.S. \& Sweden', paper presented at the Annual Meeting of the Association for the Study of Play, Rochester.

Jones, E. \& Reynolds, G., 2011, The play's the thing: Teachers' roles in children's play, Teachers College Press, New York.

Lifter, K. \& Bloom, L., 1998, 'Intentionality and the role of play in the transition to language', in A.M. Wetherby, S.F. Warren \& J. Reichle (eds.), Transitions in prelinguistic communication: Preintentional to intentional and presymbolic to symbolic, pp. 161-199, Brookes, Baltimore.

Moyles, J.R., Adams, S. \& Musgrove, A., 2002, Study of pedagogical effectiveness in early learning, Department of Education and Skills, London, viewed on 10 May 2010, from http://www.dfes.gov.uk/research

Parlett, M. \& Hamilton, D., 1987, 'Evaluation as illumination', in R. Murphy \& H Torrance (eds.), Evaluating education: Issues and methods, pp. 57-73, Harper and Row, London.

Piaget, J., 1962, Play, dreams and imitation in childhood, W.W. Norton, New York.

Rogoff, B., 1990, Apprenticeship in thinking, cognitive development in social context, Oxford University Press, Oxford.

Rogoff, B., 2003, The cultural nature of human development, Oxford University Press, Oxford.

Sandberg, A. \& Pramling-Samuelsson, I., 2003, 'Preschool teachers' play experiences then and now', Early Childhood Research \& Practice 5(1), 1-18.

Siraj-Blatchford, I. \& Sylva, K., 2004, 'Researching pedagogy in English preschools', British Educational Research Journal 30(5), 713-730.

Siraj-Blatchford, I., Sylva, K., Muttock, S., Gilden, R. \& Bell, D., 2002, Researching effective pedagogy in the early years, Department of Education and Skills, London, viewed on 12 June 2012, from http://www.dfes.gov.uk/research/data/uploadfiles/RR356.pdf
Smidt, S., 2011, Playing to teach: The role of play in the early years, Routledge, London. Sutton-Smith, B., 1997, The ambiguity of play, Harvard University Press, Cambridge.

Sylva, K., Melhuish, E., Sammons, P., Siraj-Blatchford, I. \& Taggert, B., 2004a, The effective provision of pre-school education (EPPE) project. Final report, Institute of Education, London.

Sylva, K., Melhuish, E., Sammons, P., Siraj-Blatchford, I. \& Taggart, B., 2004b, The effective provision of pre-school education (EPPE) project: Findings from pre school to end of key stage 1, Department for Education and Skills-SureStart, Nottingham.

Sylva, K., Roy, C. \& Painter, M., 1980, Childwatching at playgroup and nursery school, Grant McIntyre, London.

Umalusi, CEPD \& Wits Seminar, 2010, Will Grade $R$ really improve the quality of S.A. education?, viewed on 23 January 2015, from http://www.cepd.org. $\mathrm{za}$ /files/pictures/Final\%Report-April\%202010\%20CEPD\%20Umalusi\%20 Seminar\% $20 \% 20 \%$ Will\%20Grade $\% 20$ really\%20improve $\% 20$ the 20 quality $\% 20$ of $\% 20 \mathrm{SA} \% 20$ education.pdf

Vandenberg, B., 1986, 'Play theory', in G. Fein \& M. Rivkin (eds.), The young child at play, pp. 17-22, National Association for Education of Young Children (NAEYC), Washington.

Vygotsky, L.S., 1967, 'Play and its role in the mental development of the child', Soviet Psychology 5(3), 6-18.

Vygotsky, L.S., 1978, Mind in society: The development of higher psychological processes, MIT Press, Cambridge.

Wong, S., Wang, Z. \& Cheng, D., 2011, 'A play-based curriculum: Hong Kong children's perception of play and non-play', The International Journal of Learning 17(10), 165-180.

Wood, E., 2009, 'Developing a pedagogy of play', in A. Anning J. Cullen \& M. Fleur (eds.), Early childhood education: Society and culture, pp. 27-38, Sage, London.

WSoE (Wits School of Education), 2009, Implementation of the National Curriculum Statement in the Foundation Phase, WSoE, Johannesburg, pp. 130-153. 